\title{
Influence of Interactions in the Collaborative Solving of a Velocity Problem
}

\author{
Santa Tejeda ${ }^{1^{*}}$, Angeles Dominguez ${ }^{1,2}$ \\ ${ }^{1}$ Tecnologico de Monterrey, Monterrey, MEXICO \\ 2 Universidad Andres Bello, Santiago, CHILE \\ *CORRESPONDENCE: $\square$ stejeda@tec.mx
}

\begin{abstract}
Understanding a graph in pairs, in a productive way, improves the comprehension of a concept. In this research, we had 2 objectives: 1 ) to delve deep into the behavior of 15 pairs of remedial physics students when solving a problem with a graph of velocity, 2) to understand the interchange of personal meanings during their interactions. We posed the problem through an interview about velocity given a graph of position. We analyzed the participants' behavior based on the mathematical problem-solving theory of Schoenfeld. This analysis brought on the examination of interactions through grounded theory. We found that communication in the interchange of meanings and the quality of interactions is linked to productivity in problemsolving. We worked with a few emergent propositions based on behavior and interactions of pairs, then we identified specific alternative conceptions that students utilized to discuss the problem, how they managed their time and the richness of their contributions. Finally, we concluded that the mapping is a powerful tool that offers a view of students' mental paths while solving problems that allow to assess the nature of the conceptual models originated by the interaction.
\end{abstract}

Keywords: graphs, interactions of pairs, science education, problem solving, student behavior

\section{INTRODUCTION}

Science education at the university level is often based on the graphical representation of key concepts, such as the derivative in calculus and the velocity and acceleration in kinematics. This situation involves understanding the relationships associated with the graphical representation, in this case, of the derivative to the concepts of position, velocity, and acceleration.

The study of the relationship between the concept of derivative and position, velocity and acceleration has fostered diverse research on graph interpretation (Beichner, 1994; McDermott, Rosenquist, \& van Zee, 1987; Testa, Monroy, \& Sassi, 2002; Tuminaro \& Redish, 2003). For example, McDermott, Rosenquist and Van Zee (1987) researched how students recognize the nature of a velocity graph. This group of researchers found that the problem lies in the low association between concepts of physics and mathematics based on the participants' difficulty to select data from a graph and the lack of relationship between an original graph and a generated or associated graph. These findings emphasize the importance of a further study on the understanding of graphs.

To evaluate the interpretation and manipulation of graphs in kinematics, Beichner (1994) built the Test of Understanding Graphs in Kinematics (TUG-K) and concluded that the association of mathematical concepts to graphs, such as the derivative and integral, could make solving problems of kinematics with graphs difficult.

Article History: Received 27 September $2018 \bullet$ Revised 24 November $2018 \bullet$ Accepted 26 November 2018

(C) 2019 by the authors; licensee Modestum Ltd., UK. Open Access terms of the Creative Commons Attribution 4.0 International License (http://creativecommons.org/licenses/by/4.0/) apply. The license permits unrestricted use, distribution, and reproduction in any medium, on the condition that users give exact credit to the original author(s) and the source, provide a link to the Creative Commons license, and indicate if they made any changes. 


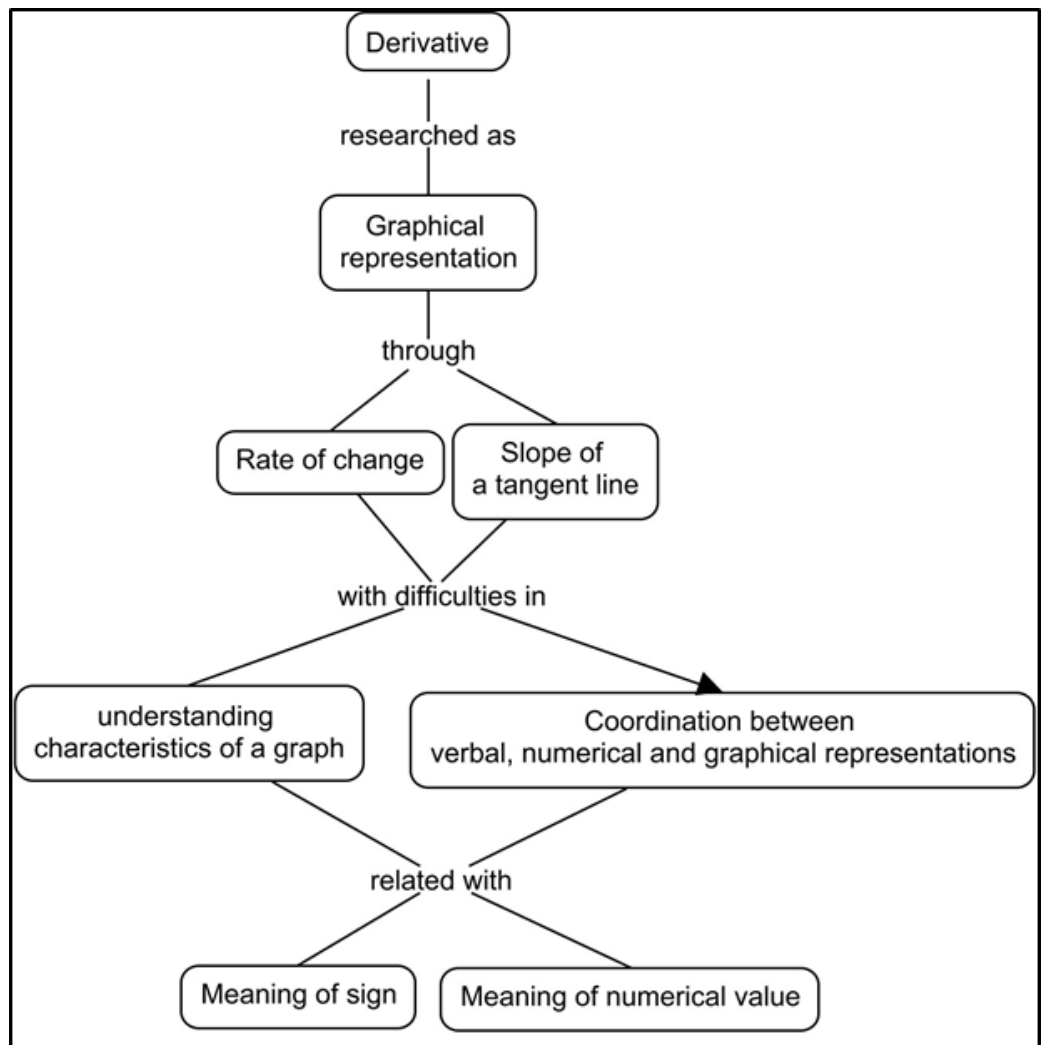

Figure 1. Problem of meanings in the graphic representation of the derivative in kinematics

Another difficulty in the notion of rate of change comes from the research of Tuminaro and Redish (2003), who reported that a kinematics student could a) not know how to use their mathematical knowledge to answer the problem, b) exclude the activation of their mathematical knowledge in their resolution strategy, and c) not connect the activated knowledge with the solution of the problem.

Tuminaro and Redish (2003) concluded that even when students apply a mathematical procedure and have an idea of the physics approach necessary to respond, they have deficiencies in handling mathematical proportions. This situation translates into problems of understanding the application of mathematical concepts to the context of physics.

Testa et al. (2002) researched reading comprehension in problems with kinematics graphs and found that students face the phenomenon as if with a lens that provided a global view, setting aside the essential characteristics of some relationships between magnitudes. The findings of Testa et al. (2002) show a tendency toward visualization difficulties, for example, in the expression of the reasoning of a problem with graphs.

These studies have reported difficulties of conceptual understanding and cognition in the interpretation of kinematic and calculus graphs. These elements delimited a research problem that requires research on the use of meaning in conceptual models of derivative in kinematics through a velocity problem with graphs. Thus, we pose the problem in Figure 1.

The meanings shown in Figure 1 shaped our objectives: to delve deeper into student performance to solve a velocity problem and understand how they interact to exchange their meanings of derivative in the framework of problem-solving. Considering all of the above, one research question arose:

What effects do interactions of Remedial Physics students have on the collaborative solving of a kinematics problem with graphs using Schoenfeld's problem-solving perspective?

\section{LITERATURE REVIEW}

The use of graphs in physics increases students' possibilities of conceptual processing. Hestenes (2003) stated that graphs are tools for analyzing information and they allow coding and comparison using mathematical representations. Furthermore, graphs can be used as a tool to understand complex concepts in 
other contexts, as it was researched by Planinic, Ivanjek, Susac, and Milin-Sipus (2013) and Evagorou, Erduran, and Mäntylä (2015). Thus, graphs can be helpful to understand concepts, but we do not know if a graph can be part of a scientific argumentation. This was the main research interest of De Cock (2012), who stated that in the graphical and pictorial format more students experience difficulty in solving the problem using physics arguments and this might be the reason for why they "fall back" to "intuitive linear reasoning".

The path to research graphs has been explored starting with the difficulties of interpreting a graph. Some researchers reported that graphs misconceptions can be found in students since as early as high school (Tejeda $\&$ Gallardo, 2017). These difficulties arise from the relation of the graphs with their elements, such as the distinction between coordinate axes. Bollen, De Cock, Zuza, Guisasola, and van Kampen (2016) examined them individually, through open-ended exams. They found conceptual difficulties in students of a physics course based on calculus as well as in students of physics based on algebra. The problem reported by Bollen et al. was the lack of distinction between two coordinate axes. Some other researchers (Dominguez, Barniol, \& Zavala, 2017) have studied student's graphical interpretation of the derivative as the slope and the antiderivative as the area under the curve when the physics context is removed, that is, from a calculus context to analyze the graphical relationship from a function to its derivative and vice versa.

The research framework that we considered involved the mental path of an individual to solve a problem. The mental path was associated with the approach to freely use a graph. In this study, we apply the Schoenfeld problem-solving model $(1985,2007)$, which states that the mental path of an individual to solve a problem goes through fundamental stages: reading, exploration, analysis, planning, implementation, transition, and verification. Each stage is broken down into activities that allow us to understand how the individual uses his or her cognitive resources and confronts a problem, whether the problem is familiar or new. The understanding obtained leads us to elements of individual performance. Two features of interest in problem-solving performance are self-regulation and reaching the implementation stage.

Schoenfeld $(1985,2007)$ stated that an effective problem solver can self-regulate his or her activities and reach the implementation stage in the mental path. In this paper, we examine the interactions of pairs of remedial physics students and consider that they can ignite problem-solving processes (Salett Biembengut \& Hein, 2004). In an effort to identify research conducted in Latin American based on Schoenfeld's framework to map student's trajectory while they are engaged in a problem solving activity, an extensive search was conducted in the principal data bases (Scopus and Web of Science). However, no articles were found that report the use of the mapping as a tool for deeper understanding of student's mathematical problem solving.

With this motivation, we developed a theoretical framework that allowed us to examine the origin and the effects of interactions in problem-solving. This framework addresses the number of members, communication characteristics, attitudes and results' production of a team. These issues are discussed below. The interaction involves an exchange of actions during a meeting, in which knowledge occurs and is assessed (Spaapen, \& van Drooge, 2011). These authors state that communication in an interaction can be scientifically robust. The interaction of interest in this research comes from an exchange of meanings between students, building a response from their interdependent contributions. Due to its characteristics, this interaction was called productive and successful. These features helped to determine research dimensions based on other nuances of productivity and level of success.

The first aspect is related to the number of members in an interaction. According to Kozlowski and Ilgen (2006), an interaction can be developed for any number of participants, and its scope is independent of this number. This position gives equal validity to the extent of two or more members, so working with pairs was not a research limitation.

The second aspect is the definition of the communication features of a collaborative team. DeChurch and Mesmer-Magnus (2010) argued that a successful team has members that collaborate effectively, in this case, to reach a correct answer. Another feature of this team is that its members exchange views to reach a joint understanding (Barron, 2000).

The third aspect of certain team interactions is its productivity. Greeno (2006) and Spaapen and van Drooge (2011) state that the characteristics of a productive interaction are: (a) the assessment of selfknowledge and knowledge of the other partner, (b) the interest in the application of knowledge generated together, and (c) exchanges of knowledge between team members produce new knowledge in turn. Kozlowski and Ilgen (2006) and Spaapen and van Drooge (2011) complement this with the attitude of interdependence. This attitude manifests itself when all team members assume a leadership role jointly. In this way, a personal goal becomes a common goal to solve tasks, clarify goals and plan results. 
A final aspect of interactions is the creation of a shared conceptual model (Barron, 2000) as a result of agreements-based communication (Bossche et al., 2010). The elements of a shared conceptual model are construction, co-construction, and constructive conflict. These elements can be found in all kinds of interactions since many interactions occur as part of a collaboration, possibly productive but not all of them applicable to solve a problem. For this reason, we believe a shared conceptual model can also arise from a very productive collaboration.

These aspects allowed us to define the first analysis of interactions of this study. The first aspect was choosing to work with pairs, being their communication the smallest team unit of analysis. The second aspect was to find productive and successful interactions. These qualities are used to focus the importance of the conceptual model built by interdependent pairs. The third aspect was the quality of success, related to a correct answer. A different search order would have excluded the possibilities of developing an elaborate response.

We designed the research problem inspired by TUG 16 (Pérez-Goytia, Dominguez, \& Zavala, 2010) and TUG-K 3.0 (Zavala, Tejeda, Barniol, \& Beichner, 2017). We analyzed the communication of student pairs to harness the wealth of the discussion generated by working in collaboration. We identified problem-solving paths based on the stages of Schoenfeld's problem-solving model (2007). Then we classified the emerging interactions regarding their productivity and success. Finally, we introduced the effects of the performance of participants in the generation and application of a shared conceptual model.

\section{METHODS AND PROCEDURES}

We worked in two phases: first, we encoded the performances of the participants by categorizing according to Schoenfeld's problem-solving model (2007) and then we applied the approach of grounded theory (Strauss, \& Corbin, 1994) as a methodological framework for data analysis. We compared the performance and interactions of pairs within a group and against other groups.

We developed matrices to determine problem-solving stages, shared conceptual models and the characteristics of the interactions. We contrasted examination of the emerging information against the theoretical framework to provide a theoretical conceptualization of the interactions of the participants. Also, we considered the qualities of productivity and success of interactions as research dimensions.

\section{Research Context}

This study was carried out at a university in northeastern Mexico. The remedial course in physics had an enrollment of approximately 400 students from 12 different sections, from which we selected 30 participants in two stages. This course is taught with elements of active learning of physics (Redish, 2003), which guides the student toward greater involvement in their own learning and provides collaborative activities.

\section{Research Participants}

The entire population answered the TUG assessment instrument and two open problems of derivative and two problems of antiderivative in calculus and kinematics, randomly evaluated. We selected the research sample using two criteria, explained below.

The first criterion involved the application of the TUG 16 (Pérez-Goytia et al., 2010) instrument. With this instrument, we evaluated the conceptual understanding and interpretation of graphs and kinematic calculation. Utilizing TUG 16, we collected information on the most appealing conceptual models.

We applied the instrument after the course covered the topic of qualitative and quantitative analysis of graphs. TUG 16 was randomly administered to the 400 students of the course so that about 200 students answered the calculus version and 200 students answered the kinematics version. Using this criterion, we identified 102 candidates to participate in the interview. Their results were assessed through the second criterion.

The second selection criterion was the implementation of four problems of the rate of change or antiderivative in calculus or kinematic randomly to all students. The four problems had the same graph and assessed the graphical interpretation of the rate of change or anti-derivative in kinematics or calculus, depending on the problem. For each problem, an answer and its justification were required.

We analyzed the relationships between concepts associated with the problem, the use of conceptual models of development and how elaborate was the justification of their answer. We identified these observable variables in the answers of 66 students placed in the third quartile TUG. We invited students to participate 
in pairs, randomly arranged for logistical reasons, with participants not knowing who their pair was beforehand. Thirty students agreed to participate. The rest declined the invitation due to unavailability of schedule.

\section{Research Design}

We applied the grounded theory approach to interviews as follows:

1. Transcripts of the participants' interviews.

2. Coding interviews according to the problem-solving theory of Schoenfeld (2007).

3. Representation of conversation in Schoenfeld's map model (Kohl and Finkelstein, 2006).

4. Analysis of the self-regulatory approach and participants in their performance.

5. Analysis of communication and duration of contributions from participants to solve the problem.

6. Constant performance comparison of pairs and the effects of their interactions.

7. Grouping of interactions of pairs based on their productivity and success into: (a) productive and successful, (b) productive and unsuccessful, (c) very productive and successful and (d) unproductive and unsuccessful.

8. Collection of causes and effects of interactions of pairs according to their classification of productivity and success.

9. Effects of interactions of pairs during the construction of a shared conceptual model.

10. Linking findings to the theoretical framework of problem solving and interactions.

The examination of the nature and effects of these interactions observes two performances combining to generate a response. Initially, the data collected had no form or structure, but we needed a first inspection to find a susceptible way to investigate. For this reason, we worked in two layers of analysis. The first layer involved the use of Schoenfeld's problem-solving theory (1985) to identify students' activities and mental paths as part of their interactions.

In the second layer of analysis, we used the grounded theory approach to investigate the extent of interactions. The focus on emerging data and newly identified categories allowed to generate specification matrices of the problem-solving stages (Schoenfeld, 1985), along with elements of the nature of the interactions.

\section{Data Collection}

We interviewed 15 pairs of students and collected their oral or written answers to solve a problem of velocity using a position graph in a reproducible classroom scenario (Duval, 2006). The emerging interactions contributed elements to answer the research question: What effects do interactions of Remedial Physics students have on the collaborative solving of a kinematics problem with graphs using Schoenfeld's problemsolving perspective?

The research technique used was the semi-structured interview (Creswell, 2005; Taylor, \& Bogdan, 1994), chosen because of its features of semi-structured protocol and flexibility of interaction. The intention was to encourage the development of interactions similar to those in the classroom (Hull, \& Saxon, 2009). The research problems discussed in the interview were based on TUG 16 (Pérez-Goytia et al., 2010).

We designed open problems similar to those found in TUG 16, from which we eliminated some options to foster elaborate responses with the possibility of examination. In the interview, we proposed that the participants answer the problems in three steps: think of the problem individually, discuss it with the partner aloud and talk with the interviewer about how they solved the problem. We delivered the written problem to the students in a sheet to share, to allow them to unify the expression of their answers. Given this scenario, we asked two questions: "What did you observe in the graph?", and "how did you use that information to solve the problem?"

We videotaped the problem solving of each pair of participants, transcribed and coded the students' answers (Figure 2) according to Schoenfeld problem-solving model (2007). 


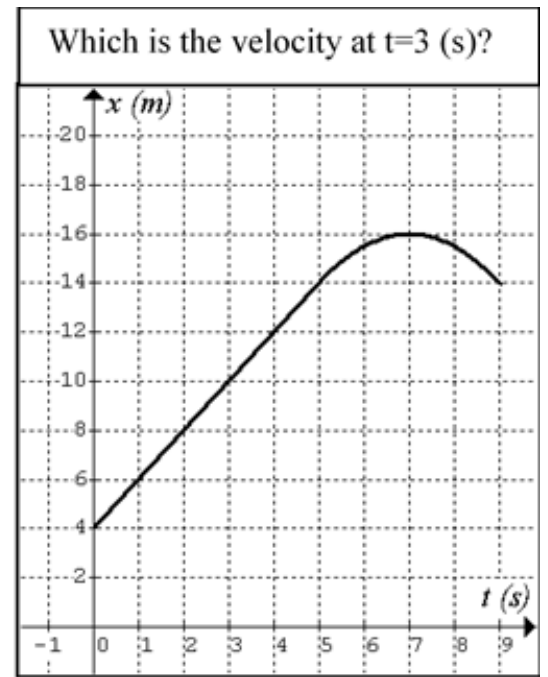

Figure 2. Problem: Find the velocity from a position graph

\section{Mapping Mathematical Talks}

To develop the Schoenfeld maps (Kohl, \& Finkelstein, 2006), we first coded the discussions according to the principles of Schoenfeld (2007), and then we represented this coding in map form. We carried out this process per student and per pair of participants in each group, generating a total of 15 Schoenfeld maps. In Appendix, we explain the categories of Schoenfeld's problem-solving stages (2007) applied to the problem of the derivative in kinematics. These categories are reading, analysis, exploration, transition, planning, implementation, and verification.

We represented these stages in relation to the time of the intervention of each participant, distributed on the horizontal axis with an equidistant spacing of 10 seconds of conversation. We started counting time once we provided the problem and stopped once the students had answered the question. The research questions did not contribute to the solution of the participants' problem. If necessary, we encouraged discussion among participants. An example of a Schoenfeld map (Kohl, \& Finkelstein, 2006) can be seen below.

The Schoenfeld map (Kohl, \& Finkelstein, 2006) pictured in Figure 3 consists of a vertical axis and a horizontal axis. On the vertical axis are the steps of problem-solving, located on top-down levels. The first level (a) is Reading, and the last level is Verification. Perpendicular to the vertical axis is the time axis (b), showing the time spent in each stage. Managerial behavior activities are outlined in the inter-stage levels and marked with a horizontal bar (c). Finally, we represented the research questions by vertical bars (d). The activities have two distinctive colors: light gray and dark gray. Each shade of gray represented a participant other than the participant partner. 


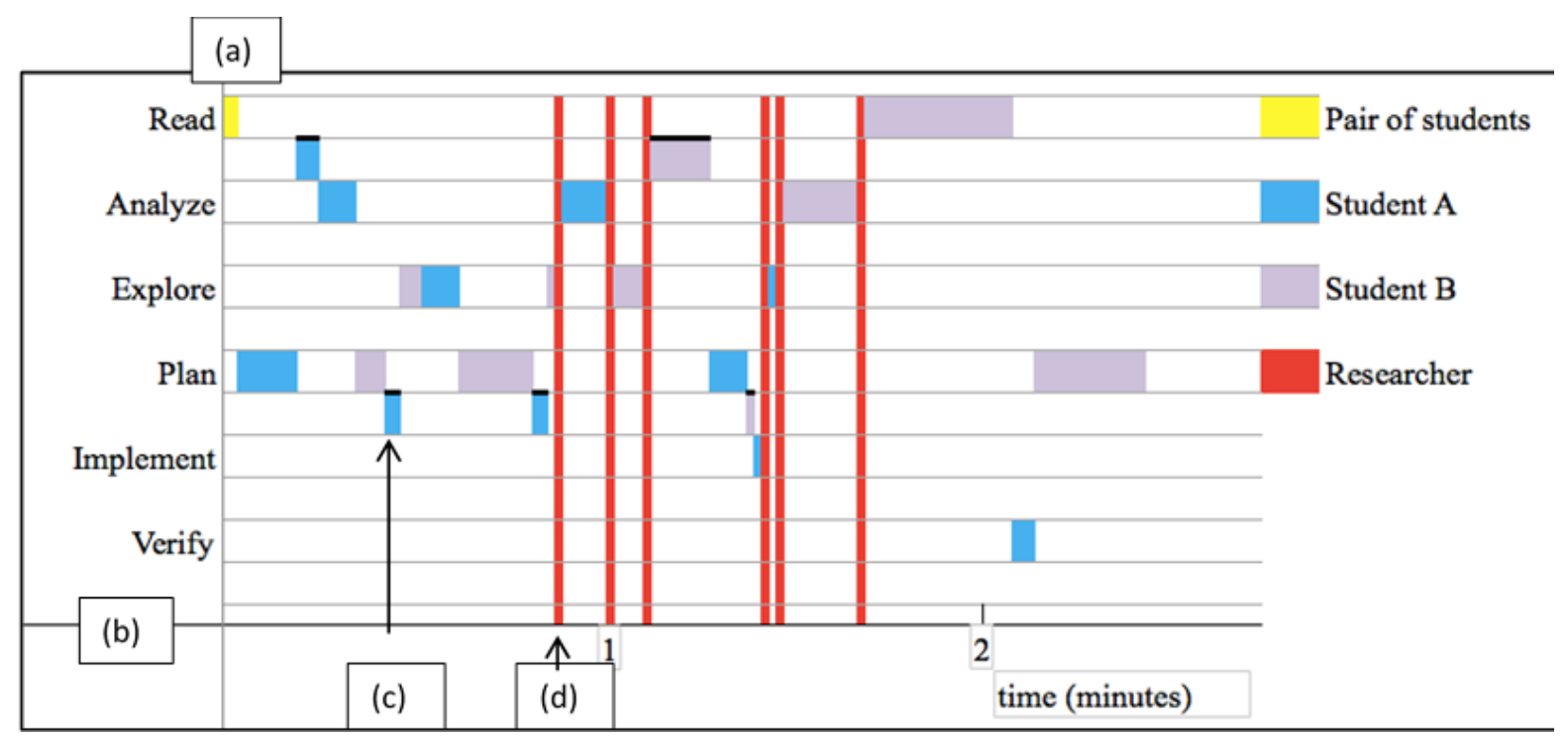

Figure 3. Map of a pair of students' problem-solving

Table 1. Groups of participants

\begin{tabular}{|c|c|c|c|}
\hline $\begin{array}{l}\text { I. Productive \& } \\
\text { successful }\end{array}$ & $\begin{array}{l}\text { II. Productive \& } \\
\text { unsuccessful }\end{array}$ & $\begin{array}{l}\text { III. Unproductive \& } \\
\text { successful }\end{array}$ & $\begin{array}{l}\text { IV. Unproductive \& } \\
\text { unsuccessful }\end{array}$ \\
\hline Alfredo \& Juan & \multirow[t]{7}{*}{ Ximena \& Gregorio } & Benjamín \& Felipe & Iván \& Miriam \\
\hline Gabriel \& Ciro & & Quetzal \& Tomás & Santiago \& Diego \\
\hline Wenceslao \& Uriel & & Yahir \& Renato & Zacarías \& Liliana \\
\hline \multirow[t]{4}{*}{ Nancy \& Perla } & & Erik \& Valentín & \\
\hline & & Hugo \& Luis & \\
\hline & & Claudio \& Ignacio & \\
\hline & & Karla \& Omar & \\
\hline
\end{tabular}

\section{Coding the Interactions}

In the second phase we conducted an in-depth examination of the maps obtained, and analyzed the meanings of stage changes and how did the contributions of each participant related to each other and the answer. The analysis included the study of stage jumps or changes and its significance, as well as contributions from participants. Jumps can provide guidance on the change of meaning and can trigger other ideas or performances (Schoenfeld, 2007). Meanwhile, contributions from participants reported their approaches to the problem or the exchange of meanings that generated the pair's answer.

We then observed how students developed a conceptual model of the rate of change, its use and its application to the problem. We also considered the effects of constructive conflict if any confrontation generated valuable content in the dialogue or answers, as well as the actions that triggered self-questioning regarding the process or the team's proposed solution. We show the grouping of the participants in Table 1.

The analysis of the routes and interactions of the participants (see Table 1) will be presented later. The result of the open and axial coding was collected into one matrix, a particular tool to grounded theory (Creswell, 2012). This matrix established a link between the emerging categories and allowed for the development of research propositions (Table 2).

These propositions were used as a test pattern of the research approach and were validated in two iterations of analysis maps (Strauss and Corbin, 1994). We will report trends in groups of participants based on their interactions. 
Table 2. Propositions of research based on Schoenfeld's stages (2007)

\begin{tabular}{ll}
\hline $\begin{array}{l}\text { Research } \\
\text { approach }\end{array}$ & Propositions \\
\hline \multirow{2}{*}{ Interactions } & Interdependence and time self-regulation can make a difference in performance in pairs. \\
\cline { 2 - 2 } & $\begin{array}{l}\text { The correct application of a conceptual model can guide the pair's process. } \\
\text { The exchange of meanings facilitates collaboration and building of a shared conceptual model. }\end{array}$ \\
\hline $\begin{array}{l}\text { Problem- } \\
\text { solving }\end{array}$ & $\begin{array}{l}\text { The exchanges are part of the pair's managerial behaviors. } \\
\text { or conceptual difficulties. }\end{array}$ \\
\cline { 2 - 2 } & Transition and verification activities can predict the chances of a pair's success. \\
\hline
\end{tabular}

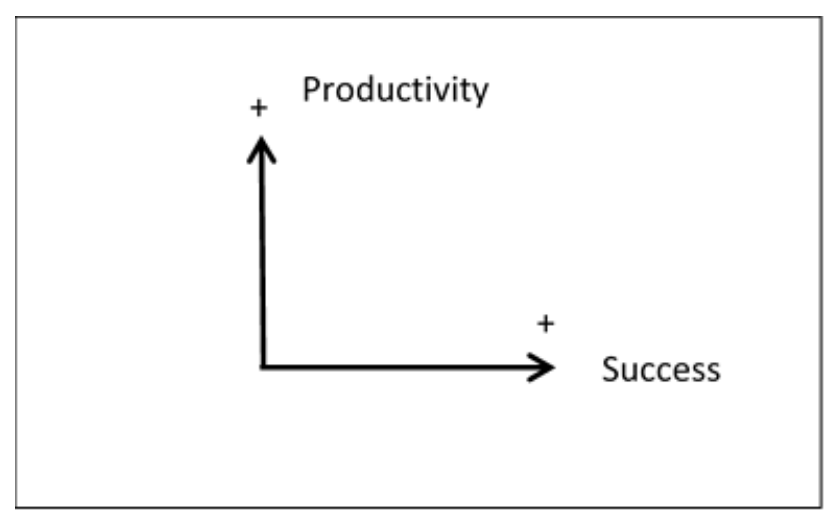

Figure 4. Classification of pairs through their interactions

Table 3. Synthesis of Schoenfeld stages (2007) of productive and successful pairs

\begin{tabular}{|c|c|c|c|c|}
\hline Stage & Alfredo \& Juan & Gabriel \& Ciro & Wenceslao \& Uriel & Nancy \& Perla \\
\hline Reading & 四 & a & a & a \\
\hline Analysis & घ & - & - & - \\
\hline Exploration & - & - & - & घ \\
\hline Planning & घ & - & घ & - \\
\hline Implementation & - & - & $\mathbf{\square}$ & - \\
\hline Verification & - & - & - & - \\
\hline Transition & - & - & $\mathbf{\square}$ & - \\
\hline
\end{tabular}

\section{DATA ANALYSIS \\ The Interactions' Framework}

The order grouping of pairs (see Table 1) is used to present the interactions' analysis and interpretation. We discuss the similarities and differences of all pairs and compare them with theoretical perspectives of problem-solving and interactions in terms of productivity and success (Figure 4).

\section{Interactions of productive and successful couples}

These pairs showed that at least one member of each pair self-regulated the problem solution and both were involved in a focused way to reach the correct answer. These interactions (see Table 1) were strong, with dialogues rich in appropriate conceptual elements to solve the problem.

\section{Similarities, differences and contrast of group I}

The pairs in group I (see Table 3) interacted strongly and harmoniously, and with substantial contributions. Initially, they reached advanced stages in their mental path. They then drafted a shared conceptual model as a result of their interaction.

\section{Similarities}

1. A single managerial behavior. We observed variations in managerial behavior location on the map: for example, Alfredo and Juan, and Wenceslao and Uriel expressed it in proximity to the analysis stage, while Gabriel and Ciro and Nancy and Perla expressed it after the implementation stage. 
Table 4. Synthesis of Schoenfeld stages (2007) of unproductive and successful pairs

\begin{tabular}{|c|c|c|c|c|c|c|c|}
\hline Episode & $\begin{array}{l}\text { Benjamín } \\
\text { \& Felipe }\end{array}$ & $\begin{array}{c}\text { Quetzal \& } \\
\text { Tomás }\end{array}$ & $\begin{array}{l}\text { Yahir \& } \\
\text { Renato }\end{array}$ & $\begin{array}{c}\text { Erik \& } \\
\text { Valentín }\end{array}$ & $\begin{array}{c}\text { Hugo \& } \\
\text { Luis }\end{array}$ & $\begin{array}{c}\text { Claudio \& } \\
\text { Ignacio }\end{array}$ & $\begin{array}{c}\text { Karla \& } \\
\text { Omar }\end{array}$ \\
\hline Reading & I & ! & ! & ! & a & I & ! \\
\hline Analysis & - & घ & - & - & - & - & - \\
\hline Exploration & घ & घ & - & - & घ & घ & घ \\
\hline Planning & 一 & घ & - & - & - & - & - \\
\hline Implementation & - & - & - & 一 & - & - & - \\
\hline Verification & 一 & - & - & - & - & - & - \\
\hline Transition & - & - & - & ! & - & - & - \\
\hline
\end{tabular}

2. Proper use of the rate of the change model: These pairs had to convince each partner or actively participate in developing the correct model.

\section{Differences}

First, we noted that Nancy and Perla, Alfredo and Juan, and Gabriel and Ciro read the problem from the beginning and analyzed it once or twice. In contrast, Wenceslao and Uriel analyzed it four times. This number suggests that one of the members was skeptical about the ideas of their partner, which could be associated with a constructive conflict. Similarly, Nancy and Perla expressed constructive conflict, which triggered a more productive path.

$\mathrm{P} \quad$ One, since otherwise, you'd be starting from here, 4. Because you wrote down 6, right?

$\mathrm{N} \quad$ Oh yes, my mistake. 6, right?

Perla's intervention showed disagreement with the improper use of the values in the equation's graph. This conflict drew a reaction from Nancy.

\section{Perspective}

Nancy verified the result of the implementation stage. The interaction between Nancy and Perla was strong and showed a path of broad ideas at the beginning and focused ones at the end. This pair showed interactions with potential, tested their approach and came up with a more elaborate model of the problem until they were satisfied with the outcome. This mental path proved the usefulness of managerial behaviors (Schoenfeld, 2007) and constructive conflicts to increase team productivity (Bossche et al., 2010), similar to the interactions between Wenceslao and Uriel. The interactions of these pairs were a result of harmonious, assertive, flexible and open dialogue between participants.

\section{Interactions of a productive and unsuccessful pair.}

This pair went through the stages of reading, analysis, planning, and implementation, and interacted strongly and showed three managerial behaviors. Ximena and Gregorio were productive with potential for success. However, we noted difficulties when using the notion of rate of change.

\section{Contrast of group II}

In the final stage of the problem, they refined their process, which involved visiting several problem-solving stages, which were classified as productive and less successful. Another aspect to consider was the three managerial behaviors of Ximena and Gregory, in contrast to the sole self-questioning found in group I.

This difference indicates that more involvement and focused self-questioning characterize productive and successful pairs. In the case of group I, their involvement had the potential to improve and required questioning the contributions of the other member, to test the strength of the conceptual model and to go through more problem-solving steps.

\section{Interactions of unproductive and successful pairs}

The mental paths of these students produced correct answers, despite communication difficulties or an arid conceptual elaboration. Visits to the implementation were located in different parts of their paths. We introduce the pairs from group III in Table 4.

\section{Similarities, differences and contrast of group III}

\section{Similarities}

The performance of these pairs (see Table 4) showed various communication difficulties: 
1. Individual elaboration, not collaborative: One of the members had some conceptual notion, while the other member did not elaborate enough to put this knowledge into play and respond correctly. For example, Benjamin and Felipe overcame their differences in communication because one of them knew the conceptual model and its application.

2. Lack of confidence to present ideas: Some pairs knew the concept of rate of change but seemed to lack the confidence to mention it from the beginning. For example, Quetzal and Thomas overcame their insecurity as a team to develop a conceptual model based on their shared knowledge.

\section{Differences}

In this group, some pairs were better connected after engaging in managerial behavior. That is, they turned to self-questioning to understand their partner. For example, Claudio and Ignacio showed how managerial behaviors can be helpful to come up with a correct answer. Also, Hugo and Luis \& Karla and Omar exchanged ideas until their managerial behaviors oriented their understanding.

K Like... another way.

O Like what, which other?

K I mean, if we chose another two points.

O Mmm, if you want, we could, like in trig... yeah

$\mathrm{K}$ I mean, if we take this.... say, 10 -writing- change in position over time change and then we put 10 minus 4, and then two less

Which is... 0?

O Yes, zero, 6 divided by 3 equals 2, it's the same.

$\mathrm{K} \quad$ It's the same.

In this conversation excerpt, we noticed that Karla's question made her partner review the proposed solution. The tenacity of Karla enriched the interaction with her partner.

Finally, two pairs from group III showed other communication difficulties: Yahir and Renato exemplified a situation in which one of them considered it was better to use assumptions rather than to develop concepts, while Erik and Valentin possibly used their concepts relying on their memory. The performance of pairs of group III would improve if their individual paths were more involved and harmonious between them, that is, that both partners could contribute back and forth during stages.

Most pairs from group III interacted strongly, while two pairs interacted weakly. This evidence led us to ponder what kind of information might explain this trend in problem-solving. We observed that the two pairs with weak interactions shared a lack of searching in their implementation.

Benjamín and Felipe only read and required research intervention to implement, while Renato and Yahir did not attempt to test the result of their mind path. The remaining pairs included implementation at different stages of their paths. Thus, this stage could be a consequence of strong interactions, in line with the principles of Schoenfeld (2007) on the importance of testing the solution.

\section{Contrast}

We contrasted the interactions of these couples with the interactions of couples in groups I and II. We found that communication of each group was very different; for example, in group I communication was open, harmonious and assertive, conducive to interdependence. Not so in group II, where communication was open but unspecific. However, we observed communication in group III showing brief exchanges of meanings, with some exceptions. We perceived that managerial behaviors and constructive conflicts enriched the performance of pairs in the group.

\section{Interactions of unproductive and unsuccessful pairs}

The performance of these pairs was unproductive, and their answers were incorrect. Pairs classified in this group were: Santiago and Diego, Zacarías and Liliana and Ivan and Miriam. One of the pairs interacted strongly and two pairs interacted weakly. 
Table 5. Synthesis of Schoenfeld stages (2007) of unproductive and unsuccessful pairs

\begin{tabular}{|c|c|c|c|}
\hline Episode & Iván \& Miriam & Santiago \& Diego & Zacarías \& Liliana \\
\hline Reading & ! & ! & ! \\
\hline Analysis & - & - & - \\
\hline Exploration & - & - & - \\
\hline Planning & - & - & - \\
\hline Implementation & - & - & - \\
\hline Verification & - & - & . \\
\hline Transition & - & . & - \\
\hline
\end{tabular}

\section{Similarities, differences and contrast of group IV}

\section{Similarities}

The interactions of these pairs showed aspects of productivity or success as a team. For example, Santiago and Diego interacted weakly and one of them held a dominant role of knowledge. The attitude of this pair was an unwillingness to interact, but we detected their intention to implement in the third stage of the problem.

Ivan and Miriam interacted weakly. It was noticeable that initially Ivan read and Miriam followed. The lack of coordination or agreements caused poor performance.

These pairs also applied a conceptual model inappropriately. Miriam implemented from $\mathrm{v}=\mathrm{d} / \mathrm{t}$ and her partner depended on her use of that model. There was a poor reception from both parties, expressed as a lack of questioning of the use of the conceptual model. This pair could improve with a personal supervision plan that included managerial behaviors.

\section{Differences}

The number of managerial behaviors and constructive conflicts made the interactions of these pairs within the group stand out. Similarly, the lack of interdependence between Ivan and Miriam and Santiago and Diego contributed to weak interactions, in which all of them shared poorly developed conceptual models. On the other hand, we observed managerial behaviors in the interaction of Zacarías and Liliana that changed the solution path but lacked self-regulation to solve the problem.

\section{Perspective}

Group IV can improve by increasing their communication skills and developing conceptual models built by both team members. Another aspect to improve is their self-questioning and self-regulation time. This observation confirms the principles of Schoenfeld (2007) on students with opportunities to encourage their problem solving, which presented similar characteristics to those observed in students from group IV.

\section{COMPARISON WITH THEORETICAL PERSPECTIVES}

This section will discuss the problem-solving stages diagram presented by all groups of participants (see Tables 3, 4 and 5). The discussion will highlight stages in common and connect our perspective with Schoenfeld's theoretical principles (2007). In this way, we establish which stages characterize the various groups of participants.

Regarding group I, the productive and successful pairs presented reading, analysis, exploration, planning, and implementation. They complemented the first part of the diagram by manifesting transition activities, such as managerial behavior. These behaviors allowed them to build correct shared conceptual models, based on harmonious and interdependent communication.

The common diagram of this group agrees with Schoenfeld's principles (2007), regardless of the number of problem solvers. Finally, two of four pairs reviewed their conceptual model, an activity that Schoenfeld (2007) recognizes as a feature of the best solvers. We believe that our results confirm the applicability of five out of six stages of problem-solving for students of a physics course with active learning elements, with limited problem-solving training.

Secondly, we explain the trends of group II, consisting of a single pair. They went through four of the first five stages. The exploration stage was missing. This absence is important, as that stage increases the perception of the graphic elements, which would have strengthened their shared conceptual model. We emphasized that the potential of this pair was based on their interdependence. We suggest that pairs with interactions of this nature need to practice how to object to their respective partner's answer. 
Thirdly, we found that less productive and successful pairs showed different paths with three key trends. The first trend was that every pair read and analyzed the problem, typical of a good start to problem-solving activities (Schoenfeld, 2007). The second trend was that six of the seven pairs planned the problem, increasing the chances of a successful and productive exchange of meanings. The third trend was that five of the seven pairs explored the problem, implemented or tested their solution and showed transition activities, such as behavior management. These three activities are crucial in the second half of the problem, as they let students test their conceptual model or measure their perspective as a team.

Our observation highlights the relevance of exploration, planning or implementation of Schoenfeld's competent problem solver (2007) for obtaining successful interactions. The examination group presented three activities that improved their problem-solving success. We think that self-regulating activities would have increased their productivity.

The fourth trend was that three out of seven pairs verified the solution. According to Schoenfeld (2007), this activity characterizes the best problem solvers. In this study, the manifestation of this activity indicates that three pairs in this group had an additional opportunity to improve their productivity.

The fifth trend of unproductive and successful pairs was that all of them read, analyzed, planned, implemented and showed transition activities. The development of these stages suggests that pairs in this group have a notion of how to solve a rate of change problem. These paths indicated that these pairs tried to solve the problem, but by giving an incorrect answer it seems that at some point they lost sight of their shared development model. For example, two of the three pairs explored and only a pair verified. We compared this stage's diagram against the diagrams of the rest of the groups and concluded that the lack of exploration and verification appear in other groups, such as groups II and III.

These trends provide a first step in the characterization of the research problem, according to the stages of Schoenfeld's problem-solving model (2007). The delimitation of this framework contributed to the examination of the interactions with the greatest potential for success. We confirm that the stages of implementation and transition are critical activities in problem-solving, capable of altering the direction of their paths. This implies that the way the pair carry out the implementation and their self-questioning about their actions increases the richness of the interaction.

Furthermore, we can summarize our results with some results from our literature review. Our results converge with the report of Planinic, Ivanjek, Susac, \& Milin-Sipus (2013) and we offer an additional point of view, because they researched with one individual, while we worked with pairs. Along the same lines, De Cock, Zuza, Guisasola, \& van Kampen (2016) worked with open-ended exams. In both cases, our findings converged, insight was gained and allowed to reach for a broader perspective.

In short, we initially tried to classify pairs. We then analyzed the difference in performance between a competent Schoenfeld solver (2007) and our participants. We realized the needed number of stages to get to the implementation stage was different, as we focused on the performance of pairs and not on that of individuals. The perception of this difference helped us to focus towards building a shared conceptual model, which included the critical activities of problem-solving exposed by Schoenfeld (2007).

\section{Shared Conceptual Models by Groups}

The answer to the problem was the product of a shared conceptual model, built by pairs during interactions. This means that the participants agreed on how to interweave the model by sharing meanings. We were interested to know the duration, the number of stages before the implementation and the number of managerial behaviors to consider all factors related to the nature of the interactions and used meanings.

The quality of interactions indicated trends in the pairs' responses. Here are the conceptual models of the participants of the productive groups:

Pairs of groups I and II (see Table 6) shared some of the factors as part of their interactions. Group I developed and successfully used the model of the rate of change of the position for speed. They reached the implementation stage as the fourth or fifth stage of their path, showed only one managerial behavior and solved the problem in a maximum time of 2 minutes. Their interactions were strong. Similarly, the productive and unsuccessful pair solved the problem in less than two minutes and showed strong interactions.

We found that the difference between groups I and II was the poor use of the model v $=d / t$, they reached the implementation stage in the eighth point of their path and they showed three managerial behaviors. This difference meant that group II lacked focus on the development of the model. This is surmised from the number 
Table 6. Shared conceptual models of groups I and II

\begin{tabular}{llccccc}
\hline Groups & Pair & $\begin{array}{c}\text { Number of stages } \\
\text { before the first } \\
\text { implementation }\end{array}$ & $\begin{array}{c}\text { Managerial } \\
\text { behaviors }\end{array}$ & Duration & $\begin{array}{c}\text { Conceptual } \\
\text { model }\end{array}$ & Interaction \\
\hline & $\begin{array}{l}\text { Alfredo } \\
\& \text { Juan }\end{array}$ & 5 & 1 & $01: 05$ & $\mathrm{v}=\Delta \mathrm{x} / \Delta \mathrm{t}$ & $\mathrm{Strong}$ \\
\hline $\begin{array}{l}\text { Wenceslao } \\
\text { Productive and } \\
\text { successful }\end{array}$ & $\begin{array}{l}\text { Gabriel } \\
\text { \& Ciro }\end{array}$ & 4 & 1 & $01: 15$ & $\mathrm{v}=\Delta \mathrm{x} / \Delta \mathrm{t}$ & $\mathrm{Strong}$ \\
\hline & $\begin{array}{l}\text { Nancy } \\
\& \text { Perla }\end{array}$ & 4 & 1 & $01: 15$ & $\mathrm{v}=\Delta \mathrm{x} / \Delta \mathrm{t}$ & $\mathrm{Strong}$ \\
\hline $\begin{array}{l}\text { Productive and } \\
\text { Unsuccessful }\end{array}$ & $\begin{array}{l}\text { Ximena \& } \\
\text { Gregorio }\end{array}$ & 5 & 1 & $02: 30$ & $\mathrm{v}=\Delta \mathrm{x} / \Delta \mathrm{t}$ & $\mathrm{Strong}$ \\
\hline
\end{tabular}

of stages at the time of implementation. On the other hand, we argue that three managerial behaviors occurred in a period comparable to that of group I. This framework leads us to argue that Group II trusted their shared conceptual model, although they did not review the feasibility of their proposed solution objectively. This observation is consistent with the explanation of the failed strategy attempts established by Schoenfeld (2007).

We return to group I (see Table 6) to review some key points of their paths. For example, the number of stages at which they reached implementation is 4 or 5 , which we interpret as a focused involvement of each member of the pair. Meanwhile, the manifestation of a single managerial behavior is related to the clarity and interdependence of their communication. Since they focused on clearly explaining their conceptual notions and objected to the viewpoint of their partner, the result of the review provided confidence in the implementation.

Communication in groups I and II played a key role in their classification as productive groups. We observed assertiveness and interdependence when creating their shared conceptual models, which were both valid. The difference in obtaining success hinged on the use of the conceptual model and the involvement of participants in their interactions.

We continue with the synthesis of shared conceptual models of groups III and IV and other factors as part of their interactions.

The pairs in groups III and IV showed a few points of coincidence (see Table 7). Both groups interacted strongly or weakly, with strong interactions in group III and weak interactions in group IV. We detected the use of $\mathrm{v}=\Delta \mathrm{x} / \Delta \mathrm{t}$ models, graphical rate of change and $\mathrm{v}=\mathrm{d} / \mathrm{t}$. We found differences in the effects of the elaborate conceptual models, possibly associated with the success of pairs in groups III and IV.

For example, group III used models $\mathrm{v}=\Delta \mathrm{x} / \Delta \mathrm{t}$ and a graphical rate of change. Team communication allowed them to develop and properly use a shared conceptual model, although they did not present enough focus and managerial behaviors. They possibly reacted late or did not realize the need to work interdependently. However, they communicated assertively, and there was some questioning of the perspective of the partner in some pairs. We suggested for them to increase their focus, according to Schoenfeld (2007).

On the other hand, group IV developed and incorrectly used the model v $=\mathrm{d} / \mathrm{t}$. Conceptual difficulties and communication hindered a successful outcome. This group reached the implementation stage in a circuitous manner, showed various managerial behaviors and solved the problem at varying times. Their interactions were weak. Group IV exemplified how a lack of focus and involvement contributed to the development of weak interactions.

The scattered stages visited to reach implementation evidenced a lack of focus. Both the pair that needed to go through nine stages before implementing and the pair that did not test their proposed solution showed unsuccessful attempts at solving the problem. Moreover, assertive and harmonious communication opens the door to self-questioning or managerial behaviors that allow participants to review the feasibility of the model. This communication was not observed in group IV, which accounted for the weak interactions. 
Table 7. Shared conceptual models of groups III and IV

\begin{tabular}{|c|c|c|c|c|c|c|}
\hline Group & Pair & $\begin{array}{c}\text { Number of stages } \\
\text { before the first } \\
\text { implementation }\end{array}$ & $\begin{array}{l}\text { Managerial } \\
\text { behaviors }\end{array}$ & Duration & $\begin{array}{l}\text { Conceptual } \\
\text { model }\end{array}$ & Interaction \\
\hline \multirow{7}{*}{$\begin{array}{l}\text { Unproductive\& } \\
\text { successful }\end{array}$} & $\begin{array}{l}\text { Benjamín \& } \\
\text { Felipe }\end{array}$ & 4 & 0 & 01:05 & $\mathrm{v}=\Delta \mathrm{x} / \Delta \mathrm{t}$ & Weak \\
\hline & $\begin{array}{l}\text { Erik \& } \\
\text { Valentín }\end{array}$ & 0 & 2 & $01: 10$ & $\mathrm{v}=\Delta \mathrm{x} / \Delta \mathrm{t}$ & Strong \\
\hline & $\begin{array}{l}\text { Renato \& } \\
\text { Yahir }\end{array}$ & 0 & 2 & 01:30 & $\begin{array}{l}\text { Graphical } \\
\text { rate of change }\end{array}$ & Weak \\
\hline & $\begin{array}{l}\text { Quetzal \& } \\
\text { Tomás }\end{array}$ & 10 & 0 & 01:35 & $\mathrm{v}=\Delta \mathrm{x} / \Delta \mathrm{t}$ & Strong \\
\hline & $\begin{array}{l}\text { Karla \& } \\
\text { Omar }\end{array}$ & 7 & 5 & $01: 57$ & $\mathrm{v}=\Delta \mathrm{x} / \Delta \mathrm{t}$ & Strong \\
\hline & $\begin{array}{l}\text { Claudio \& } \\
\text { Ignacio }\end{array}$ & 11 & 4 & 02:05 & $\mathrm{v}=\Delta \mathrm{x} / \Delta \mathrm{t}$ & Strong \\
\hline & $\begin{array}{l}\text { Hugo \& } \\
\text { Luis }\end{array}$ & 12 & 4 & $02: 30$ & $\mathrm{v}=\Delta \mathrm{x} / \Delta \mathrm{t}$ & Strong \\
\hline \multirow{3}{*}{$\begin{array}{l}\text { Unproductive \& } \\
\text { unsuccessful }\end{array}$} & $\begin{array}{l}\text { Santiago \& } \\
\text { Diego }\end{array}$ & 0 & 0 & 01:05 & $\mathrm{v}=\mathrm{d} / \mathrm{t}$ & Weak \\
\hline & $\begin{array}{l}\text { Iván \& } \\
\text { Miriam }\end{array}$ & 3 & 1 & $02: 40$ & $\mathrm{v}=\mathrm{d} / \mathrm{t}$ & Weak \\
\hline & $\begin{array}{l}\text { Zacarías \& } \\
\text { Liliana }\end{array}$ & 10 & 7 & $04: 30$ & $\mathrm{v}=\mathrm{d} / \mathrm{t}$ & Strong \\
\hline
\end{tabular}

\section{CONCLUSIONS}

The examination of the interactions of 15 pairs of students raised several research challenges. The first challenge was to extend the concept of the performance of a problem solver to the effects of pair interaction. We addressed this challenge by using Schoenfeld maps (2007), which reported a quantifiable perspective of each pair's path. Then we represented this information on a map indicating the stages visited by each participant based on time (Kohl and Finkelstein, 2006). This map highlights the path of a solution of each pair and displays the time devoted to that activity. The classification of Schoenfeld stages (2007) for the interviewed pairs worked as a starting point for the study of the emergence of their interactions.

As a second challenge, we perceived the need to design a rigorous strategy of analysis with communication elements to facilitate the examination of group speech. We solved this need by defining aspects of examination of interactions, from which various categories emerged.

The third challenge was to find the structure of all the factors related to the study of interactions and provide a response both to the stages of problem-solving as to the study of the interactions. For this reason, we proposed to carry out the study on two levels: a micro level from Schoenfeld's principles (2007) and a macro level from the analysis of interactions, based on the criteria of interpretation built specifically for this research.

Confronting the challenges allowed us to respond to the research question initially raised: What effects do interactions of Remedial Physics students have on the collaborative solving of a kinematics problem with graphs using Schoenfeld's problem-solving perspective?

This answer comes in three parts:

(a) In productive interactions, students that generate successful interactions tend to exchange kinematics approaches, they question their procedures and actively listen to the what their partner has to say. Their interdependent point of view transforms individual perspectives into a meaningful joint effort. This finding confirms Schoenfeld's principle (2007) on the attempts to search for meaning when solving a problem. Another finding in these interactions was that students contribute meaningful elaborations, moderated or self-regulated by the team and show an involvement from the early stages of the problem, reflected in interest in reaching implementation.

(b) The dividing line between productive and poorly productive interactions is based on Schoenfeld's principles (2007) on the self-regulation of a team. We know that members of the couples had not worked together before, as they belonged to different sections of the course. However, there were couples in 
group I and II who overcame this lack of familiarity with communication and immediately became assertive and interdependent. However, the time investment that characterized the group of unproductive pairs was reflected in other critical activities for the successful resolution of the problem, such as a proper path to the implementation, a correct application of the shared conceptual model and a self-questioning process to guide the development of the problem effectively.

(c) Students struggling to exchange perspectives maintained an impractical conceptual model or of limited application to address the problem. These students were unwilling to share a substantial personal perspective or to question their partner's contribution to combine elements and build a viable and correct conceptual model. Our observations confirm Schoenfeld's principles (2007) on the transition activities, which in our research manifested as managerial behaviors.

The grounded theory approach leads us to identify the differentiating characteristics of team performance, namely their ability to develop a shared conceptual model of the rate of change in kinematic in groups and their communication. The analysis of these characteristics allows us to state that interactions vary regarding productivity and success. We started with the concept of interdependent students, self-regulating and exchanging knowledge who tend to successfully build a shared conceptual model of the rate of change and contrasted this conception against the groups identified throughout the study.

\section{Future Research}

Further research needs to be developed using Shoenfeld' framework and mapping tool to better understand students' conception of derivatives. For instance, having students engage in problem solving that use the concept of derivatives in other contexts, such as, biology, chemistry, business and managerial situations. By widening the analysis of students' understanding of the uses of derivatives in other contexts and their problem solving trajectories, researchers could better understand the impact of the context of the learning of the derivative concept.

Given the relationship between the concept of derivative and the concept of integral, graphical situations that involve the concept of integrals could enrich the understanding of the interplay that allows a graphical interpretation from a function to its derivative and from the derivative back to the function. This study is complemented by investigating students' problem solving trajectories while working in problem situations that require the understanding and interpretation of the area under the curve.

Moreover, to investigate students' interaction in problem solving situations that involve fundamental concepts of calculus, such as derivatives and integrals, in different academic levels (freshman, sophomore, junior, and senior) could be interesting in terms of mapping their collaboration to determine how productive and successful their path is as their ideas mature over time.

\section{Contribution of this Paper to the Literature}

We consider the resulting criteria as a fundamental part of this examination. Its scope includes the length of the path, the problem-solving map, the interpretation of the path, the conceptual model brought into play, the number of stages to implementation, the idea exchanges of the pairs and reporting on the quality of interaction. The strength of this approach lies on two aspects: 1) the elements are intertwined, providing sense to a problem addressed in the literature and 2) foster a view that integrates the crucial aspects of a pair's path.

We observed the effects of interactions through paths after conceptual conflict management and collaborative behaviors detected in solving a problem of kinematics. We confirm that managerial behaviors were conducive to more focused paths, which confirm this Schoenfeld's principle (2007).

The contribution of this work to the body of research on problem-solving kinematics and collaborative work aims to present the relevance of these effects on interactions that are productive and successful, productive and unsuccessful, unproductive and successful and unproductive and unsuccessful, and also structure a way to represent the evolution of the understanding of a conceptual notion in a velocity problem.

\section{Acknowledgements}

This research was funded by the Physics Education Research and Innovation Group of Tecnológico de Monterrey campus Monterrey. 


\section{Disclosure statement}

No potential conflict of interest was reported by the authors.

\section{Notes on contributors}

Santa Tejeda - Lecturer and researcher of the Science Department in the School of Engineering and Sciences and research collaborator of the Innovation and Research in Education Group and of the Master in Education Program in the School of Humanities and Education at the Tecnologico de Monterrey.

Angeles Dominguez - Professor of the Department of Mathematics in the School of Engineering and Sciences, researcher in the School of Humanities and Education, and Associate Dean of Faculty Development in the School of Medicine and Health Sciences at the Tecnologico de Monterrey, Mexico. Also, she is currently collaborating with the School of Engineering at the University Andres Bello, Santiago, Chile.

\section{REFERENCES}

Barron, B. (2000). Achieving coordination in collaborative problem-solving groups. Journal of the Learning Sciences, 9(4), 403-436. https://doi.org/10.1207/S15327809JLS0904_2

Beichner, R. (1994). Testing student interpretation of kinematics graphs. American Journal of Physics, 62, 750-762. https://doi.org/10.1119/1.17449

Bossche, P., Gijselaers, W., Segers, M., Woltjer, G., \& Kirschner, P. (2010). Team learning: building shared mental models. Instructional Sciences, 39, 283-301. https://doi.org/10.1007/s11251-010-9128-3

DeChurch, L. A., \& Mesmer-Magnus, J. R. (2010). The cognitive underpinnings of effective teamwork: a metaanalysis. The Journal of applied psychology, 95(1), 32-53. https://doi.org/10.1037/a0017328

De Cock, M. (2012). Representation use and strategy choice in physics problem solving. Physical Review Special Topics-Physics Education $\quad$ Research, 020117. https://doi.org/10.1103/PhysRevSTPER.8.020117

Dominguez, A., Barniol, P., \& Zavala, G. (2017). Test of understanding graphs in calculus: Test of students' interpretation of calculus graphs. EURASIA Journal of Mathematics, Science and Technology Education, 13(10), 6507-6531. https://doi.org/10.12973/ejmste/78085

Duval, R. (2006). A cognitive analysis of problems of comprehension in a learning of mathematics. Educational Studies in Mathematics, 61(1/2), 103-131. https://doi.org/10.1007/s10649-006-0400-z

Evagorou, M., Erduran, S., \& Mäntylä, T. (2015). The role of visual representations in scientific practices: from conceptual understanding and knowledge generation to 'seeing' how science works. International Journal of STEM Education, 2(1), 11. https://doi.org/10.1186/s40594-015-0024-x

Greeno, J. G. (2006). Theoretical and practical advances through research on learning. In: J. L. Green et al., (Eds.), Handbook of complementary methods in education research (pp. 795-806). Mahwah, N.J.: Routledge.

Hull, D. M., \& Saxon, T. F. (2009). Negotiation of meaning and co-construction of knowledge: An experimental analysis of asynchronous online instruction. Computers \& Education, 52(3), 624-639. https://doi.org/10.1016/j.compedu.2008.11.005

Kohl, P., \& Finkelstein, N. (2006). Effects of representation on students solving physics problems: A finegrained characterization. Physical Review Special Topics - Physics Education Research, 2(1), 010106. https://doi.org/10.1103/PhysRevSTPER.2.010106

Kozlowski, S. W.J., \& Ilgen, D. R. (2006). Enhancing the effectiveness of work groups and teams. Psychological Science in the Public Interest, 7(3), 77-124. https://doi.org/10.1111/j.1529-1006.2006.00030.x

McDermott, L. C., Rosenquist, M. L., \& Van Zee, E. H. (1987). Student difficulties in connecting graphs and physics: Examples from kinematics. American Journal of Physics, 55(6), 503-513. https://doi.org/10.1119/1.15104

Pérez-Goytia, N. F., Domínguez, A., \& Zavala, G. (2010). Understanding and interpreting calculus graphs: refining an instrument. In: S. Mel, C. Singh, y N. S. Rebello (Eds.), Physics Education Research Conference Proceedings (Vol. 1289, pp. 249-252). Portland, Oregon: American Institute of Physics. https://doi.org/10.1063/1.3515213 
Planinic, M., Ivanjek, L., Susac, A., \& Milin-Sipus, Z. (2013). Comparison of university students' understanding of graphs in different contexts. Physical Review Special Topics-Physics Education Research, 9(2), 020103. https://doi.org/10.1103/PhysRevSTPER.9.020103

Redish, E. F. (2003). Teaching physics with the physics suite. USA: John Wiley and Sons.

Salett Biembengut, M., \& Hein, N. (2004). Modelación matemática y los desafíos para enseñar matemática. Educación Matemática, 16(2), 105-125.

Schoenfeld, A. H. (1985). A framework for the analysis of mathematical behavior. In: Mathematical problem solving (pp. 14-15). Londres: Academic Press. https://doi.org/10.1016/B978-0-12-628870-4.50007-4

Schoenfeld, A. H. (2007). What is mathematical proficiency and how can it be assessed? In: A. H. Schoenfeld, (Ed). Assessing mathematical proficiency (pp. 59-73). Mathematical Science Research Institute Publications. https://doi.org/10.1017/CB09780511755378.008

Spaapen, J., \& van Drooge, L. (2011). Introducing "productive interactions" in social impact assessment. Research Evaluation, 20(3), 211-218. https://doi.org/10.3152/095820211X12941371876742

Strauss, A., \& Corbin, J. M. (1994). Grounded theory methodology. In: N. K. Denzin y Y. S. Lincoln, (Eds.), Handbook of qualitative research (pp. 273-285). Thousand Oaks: Sage Publications.

Taylor, S. J., \& Bogdan, R. (1994). Introducción a los métodos cualitativos de investigación (2nd Ed.), Barcelona, España: Ediciones Paidos.

Tejeda, S., \& Gallardo, K. E. (2017). Performance Assessment on High School Advanced Algebra. International Electronic Journal of Mathematics Education, 12(9), 777-798.

Testa, I., Monroy, G., \& Sassi, E. (2002). Students' reading images in kinematics: the case of real-time graphs. International Journal of Science Education, 24(3), 235-256. https://doi.org/10.1080/ 09500690110078897

Tuminaro, J., \& Redish, E. F. (2003). Understanding Students' Poor Performance on Mathematical Problem Solving In Physics. In J. Marx, S. Franklin, \& K. Cummings, (Eds.), Physics Education Research Conference (Vol. 720, pp. 113-116). Madison, WI: American Institute of Physics.

Zavala, G., Tejeda, S., Barniol, P., \& Beichner, R. J. (2017). Modifying the test of understanding graphs in kinematics. Physical Review Physics Education Research, 13(2), 020111. https://doi.org/10.1103/ PhysRevPhysEducRes.13.020111 


\section{APPENDIX}

\section{Categories of Problem-solving Applied to the Problem of Derivative in Kinematics}

\begin{tabular}{ll}
\hline Stage & Description \\
\hline Reading & It is typically the student's first approach to the problem. It is observed during the initial \\
& approach to the problem or during an inspection, such as an instant review because of an \\
interview question.
\end{tabular}

